\title{
Christiane Chaulet Achour (dir.), Frantz Fanon, «Mon Fanon à moì
}

\section{Claudia Mansueto}

\section{(2) OpenEdition}

10 Journals

\section{Édition électronique}

URL : http://journals.openedition.org/studifrancesi/3907

DOI : 10.4000/studifrancesi.3907

ISSN : 2421-5856

Éditeur

Rosenberg \& Sellier

\section{Édition imprimée}

Date de publication : 1 décembre 2012

Pagination : 622-623

ISSN : 0039-2944

\section{Référence électronique}

Claudia Mansueto, «Christiane Chaulet Achour (dir.), Frantz Fanon, «Mon Fanon à moi»», Studi Francesi [En ligne], 168 (LVI | III) | 2012, mis en ligne le 30 novembre 2015, consulté le 06 mars 2021. URL : http://journals.openedition.org/studifrancesi/3907 ; DOI : https://doi.org/10.4000/studifrancesi.3907

Ce document a été généré automatiquement le 6 mars 2021.

\section{(c) (i) (9)}

Studi Francesi è distribuita con Licenza Creative Commons Attribuzione - Non commerciale - Non opere derivate 4.0 Internazionale. 


\title{
Christiane Chaulet Achour (dir.), Frantz Fanon, «Mon Fanon à moi»
}

\author{
Claudia Mansueto
}

\section{RÉFÉRENCE}

CHRISTIANE CHAULET ACHOUR (dir.), Frantz Fanon, «Mon Fanon à moi», «Algérie Littérature/

Action», nn. 153-156, septembre-décembre 2011, pp. 153.

Dédié à Frantz Fanon, ce numéro d'«Algérie Littérature/Action» comprend trente-deux contributions partagées en trois sections: «Pour Frantz Fanon» 1961-2008 (pp. 13-34); «Hommages 2011» (pp.35-121) et «Photographies» (pp. 122-153). Psychiatre et intellectuel engagé dans la guerre de libération algérienne, le martiniquais Frantz Fanon (1925-1961) est un exemple d'indéniable valeur idéologique et morale pour tous ceux qui consacrent leur vie à la «libération de l'homme» (p.7). Porte-parole des humiliations vécues par l'Algérie colonisée, Fanon exhorte les algériens à la révolte, une violence finalisée à la construction d'une nation démocratique où, comme dira plus tard Malika Mokeddem, les «algé-riens pourront devenir algé-rois» (Malika Mokeddem, Des rêves et des assassins, Paris, Grasset, 1995, p. 67). Généreux et courageux, Fanon laisse à ses lecteurs un héritage important: pour défendre ses propres principes, il faut, comme souligne Aimé Césaire «Se donner. Tout entier. Sans réticence. Sans partage» (p. 13). «Homme de pensée et homme d'action» (p. 14), Fanon est, selon Anna GREKI, un «cri poignant» (p. 25) qui continue à orienter le processus de désaliénation du malade, du prisonnier, du faible, de l'homme seul. «Homme vivant, sans cesse en mouvement, en questionnement, éternellement jeune» (p.35), Fanon exhorte ses amis à la communication, au dialogue parce que c'est la parole qui libère l'opprimé, qui donne un espoir aux damnés de la terre.

«Revue engagée dans une action de longue haleine liée au présent de la création plurielle des deux rives» (p. 10), «Algérie Littérature/Action», comme met en évidence Marie VIRolle, n'a pas pour «habitude de publier des commémorations» (p.11) parce 
que la revue s'occupe surtout de la diffusion de toutes ces créations «métissée[s], migrante[s] ou marginalisée[s]» (p. 10) qui risquent de succomber sous le poids d'une littérature homologuée. Mais, alors, pourquoi «Algérie Littérature/Action» décide-telle de rendre hommage à un homme disparu en 1961? Virolle nous rappelle que «Fanon inspire» (p. 10) parce qu'il est un intellectuel atypique, sui generis: soldat parmi les soldats, paysan parmi les paysans, malade parmi les malades, il a partagé l'agonie du peuple algérien, il a lutté avec ceux qui ont «dit non à la servitude» (p. 61). La lecture de Frantz Fanon, «Mon Fanon à moi» permet de connaître la pensée ouverte et anticonformiste d'un intellectuel qui a dédié toute sa vie à la naissance de l'«Homme Neuf» (p. 81), d'un individu fier de son identité, orgueilleux de sa divergence. L'exemple de Fanon a éclairci le vide idéologique qui suffoquait le peuple algérien, son message optimiste a conduit le peuple maghrébin hors de la caverne de l'inanité parce que, comme nous le rappelle Christiane Chaulet Achour, «Le jour nouveau qui déjà se lève doit nous trouver fermes, avisés et résolus» (p. 77). 